\title{
Perspectives of Pharmacists on the Structure, Decision-Making, and Communication Practices of Multidisciplinary Cancer Teams in Alabama
}

\author{
Moano Gnagna-Waka, PharmD Candidate 2021루 ;eorges Adunlin, PhD, MA, MSEd ${ }^{1}$; Katie Boyd, PharmD, BCPS ; \\ Patricia Jumbo-Lucioni, MD, PhD ${ }^{1,2}$; Bolanle Bolaji MD, MPH ${ }^{3}$; Matthew Asare, PhD, MPH, MBA, CHES \\ ${ }^{1}$ Samford University McWhorter School of Pharmacy, Birmingham, AL \\ ${ }^{2}$ Department of Biological Sciences, College of Arts and Science, University of Alabama at Birmingham \\ ${ }^{3}$ Department of Epidemiology, School of Public Health, University of Alabama at Birmingham, Birmingham, AL \\ ${ }^{4}$ Department of Public Health, Baylor University, Baylor, TX
}

\begin{abstract}
Introduction: A multidisciplinary team (MDT) approach within cancer care settings is increasingly being adopted to improve patient outcomes due to the rising complexity of diagnosis and treatment. This study aims to explore the perspective of pharmacists on the structure, decision-making process, and communication practices of cancer MDTs. Methods: A 25-item online questionnaire was distributed to oncology-related clinical pharmacists in Alabama. Data were analyzed using descriptive statistics. Results: $A$ total of 15 pharmacists completed the survey. More than half of the respondents reported that MDT meetings were held mostly in person on a set schedule. While physicians primarily facilitated the meetings, patients and/or their caregivers were largely not invited to participate in them. The treating physician oversaw delivering and update to the patient and/or their caregivers after the MDT meetings. Most respondents indicated that positron emission and computed tomography were the most common sources of information available at initial case presentations. Overall, respondents strongly agreed that they felt comfortable sharing their opinions with others health professionals during MDT meetings. Conclusions: This study provides evidence that oncology pharmacists are involved in MDT decisionmaking processes and communications but suggests the need to promote conditions to further their participation.
\end{abstract}

Keywords: pharmacist; multidisciplinary team; cancer; shared decision-making

\section{INTRODUCTION}

The collaboration of healthcare professionals across various specialties can improve treatment outcomes, particularly in complex conditions ${ }^{1,2}$. Thus, in the last decade, a multidisciplinary team (MDT) approach has gradually taken a significant role in patient management worldwide. ${ }^{3,4}$ This has led to the establishment of multidisciplinary treatment planning teams, an integrated team approach to healthcare in which medical and allied healthcare professionals, including pharmacists, combine their expertise to generate a comprehensive and coordinated patient care plan. ${ }^{5}$ These groups of specialists collaborate to synergize patient treatment based on numerous considerations at the patient and organizational levels to establish clinical guidelines. Emerging evidence found that the MDT approach is increasingly recognized as best practice in healthcare delivery to improve patient satisfaction and outcomes and enhance the quality of clinical care. ${ }^{6,7}$

According to the Institute of Medicine, collaborative teambased care is recommended for cancer patients because of the increasing complexity of cancer diagnoses, staging, and treatment. $^{8}$ The management of cancer patients, especially those with metastatic and advanced stages presents unique

Corresponding author: Georges Adunlin, PhD, MA, MSEd Samford University McWhorter School of Pharmacy Birmingham, AL

Email: gadunlin@samford.edu challenges to healthcare providers. ${ }^{9-11}$ Cancer patients often require complex medical and supportive care, as well as ongoing follow-up care, including managing the short-term side effects of treatment as well as surveillance for long-term side effects or complications, such as recurrence ${ }^{12,13}$. Prior studies show that the management of cancer patients requires the expertise of a MDT to formulate an optimal treatment strategy. ${ }^{14,15}$ Even though several studies have shown improved outcomes in cancer associated with the use of MDTs when compared to conventional services, ${ }^{16}$ others showed limited evidence linking MDTs with improvement in patient outcomes and survival. ${ }^{16,17}$ The MDT approach in cancer care has been in existence for a long time in the United States. ${ }^{18-20}$ However, very little is known about how MDTs function across numerous factors, such as the type of healthcare facility (e.g., general hospitals, university hospital, cancer center), availability of healthcare providers, specialties of healthcare providers, the volume of patients and the types of patients treated. Thus, it is necessary to have a better understanding how these MDTs operate.

For MDTs to be successful, they must combine a large amount of information from several sources to make a clinical decision. ${ }^{21,22}$ Clinical Decision Support Tools (DST), also known as decision aids, help to improve the quality of the decision, the extent to which the choices of healthcare providers are congruent with their informed and considered values in the presence of uncertainty. ${ }^{23,24}$ Studies have shown that welldesigned, targeted clinical DSTs have the potential to improve patients' health outcomes and allow providers to adhere to 
guidelines recommendations. ${ }^{25-28}$ The active adoption of clinical DSTs in practice has been very slow for various reasons, including difficulty incorporating them into a provider's work, and the provider's fear of losing the patients' respect. ${ }^{27,29,30}$ Clinical DSTs are well suited to support MDT meetings, ${ }^{25,31}$ as they add a great benefit in structuring the decision-making process. $^{32}$ Despite this, little is known about the types and effectiveness of DSTs in cancer MDT settings.

Consistent and effective communication between team members is also vital to ensure productivity and continuity. ${ }^{33,34}$ There are many challenges to effective communication between health professionals, including the synchronous nature of communication, the diversity in the education and training of health professionals, and the impact of hierarchy. ${ }^{33,35}$ It is imperative to identify the factors that constitute effective and ineffective communication and determine how communication can facilitate team functioning to overcome barriers and maximize benefits. The objective of this study is threefold: (1) assess the variety of ways in which MDTs are structured and implemented in cancer care; (2) identify the support tools used to make decisions and (3) examine the communication practices amongst teams, all from the perspective of pharmacists.

\section{METHODS}

\section{Conceptual framework}

The conceptual framework for MDT meetings in stroke rehabilitation was adapted to guide the design of this study. ${ }^{36}$ The model offers a general view of how a MDT is structured and the team operates. The model is built on four basic elements: 1 ) the overall context in which the meeting operated; 2 ) inputs (personal attributes of the staff, format and structure of the meetings); 3) the processes which mediated the inputs (team climate and leadership/chairing); 4) desired outputs such as clinical decisions and the attributes of successful meetings identified by staff members.

\section{Questionnaire development and items}

The questionnaire was developed by using the Multidisciplinary Treatment Planning Questionnaire, an instrument developed by the National Cancer Institute. ${ }^{37}$ Specifically, this pre-existing questionnaire was adopted and revised with permission from the corresponding author. To ensure that survey questions address the study goals and objectives, four clinical pharmacy faculty evaluated the instrument. Faculty were selected based on their knowledge of the topic, and their availability to assess the survey. These experts were supplied with the first draft of the questionnaire and asked to assess the clarity of the questionnaire's items, and the face validity of the instrument (i.e., does the instrument evaluate what it is intended to evaluate). Their feedback was collected and used to refine the instrument and generate a second draft. The second draft resulted in a number of modifications in terms of phrasing and format. First, the initial instrument had 29 questions, which were scaled down to 25 questions. The four questions were excluded because they addressed information redundant to that of other questionnaire items. Second, the exhaustive list of cancer was grouped into six general types: carcinoma, sarcoma, myeloma, leukemia, lymphoma, and mixed types. Third, grammatical errors were corrected. The reliability of the questionnaire was determined using Cronbach's coefficient alpha. The reliability of the four main sections of the questionnaire was also analyzed. The overall instrument had a good reliability with a Cronbach's alpha of 0.822 . The testing of the instrument achieved optimal Cronbach's alpha in each domain: structure of multidisciplinary treatment planning (Cronbach's alpha $=0.831)$, patient involvement (Cronbach's alpha $=0.772$ ), decision support of MDT meetings (Cronbach's alpha =0.857), MDT communication and satisfaction (Cronbach's alpha $=0.799$ ).

The 25-item questionnaire was used for data collection, which included both closed-ended and open-ended items. The first part of the survey questionnaire assessed the structure of the MDT planning for cancer care at the participant's institution. The second section inquired about the patient involvement in the MDT planning meeting at the respondent's institution. The third section asks questions about the decision-making process and the decision support tools employed in MDT planning for cancer patients at the participant's institution. The fourth section focused on how the MDT members communicate among themselves and with patients. The fourth section also inquires whether the respondent is satisfied with the MDT planning at their institution. The fifth and last section collected information on the demographic characteristics and specialty group of the respondent.

\section{Target population and survey administration}

The survey population consisted of oncology pharmacists. We specifically targeted oncology pharmacists practicing in the state of Alabama who actively provided direct care to cancer patients and were members of a multidisciplinary cancer team. The survey was deployed using Qualtrics survey software (Qualtrics XM, Provo, UT, USA). Requests to participate were sent via email to eligible oncology pharmacists. Given the lack of oncology pharmacist association in Alabama, we anticipated that potential participants in our study may be reached effectively through referrals by oncology pharmacists recruited initially in the study. ${ }^{38,39}$ Hence, the snowball sampling technique was used for data collection. ${ }^{38,39}$ Snowball sampling is a recruitment technique in which research participants are asked to assist researchers in identifying other potential subjects. Alabama oncology pharmacists were identified using an online search and asked to participate in the survey via email. When a subject was contacted, they were asked to refer colleagues to take part in the study. To encourage survey completion, one electronic reminder notification was sent via Qualtrics at a seven-day interval. A cover letter explaining the nature of the study was presented, and respondents were assured that complete confidentiality would be preserved and that only aggregated data would appear in publications or reports. The Samford University Institutional Review Board approved the study. Data was collected between August 9th, 2020 until November 9th, 2020. 


\section{Statistical analysis}

Respondents' demographic and practice characteristics were summarized using descriptive statistics (frequencies, mean, and standard deviation). Frequencies and percentages were used to describe the response to opinion questions. Data analysis was conducted using Stata Version 14 (StataCorp LP, College Station, TX, USA).

\section{RESULTS}

Population demographics

The demographic characteristics of the respondents are reported in Table 1. Fifteen oncology pharmacists completed the survey. Most of the respondents were female (53\%), between the age group of 35-44 (80\%), had between 6 to 10 years of work experience in their specialty group, including residency $(47 \%)$, and classified their department as oncology pharmacy (33\%; Table 1). The majority of the respondents classified their institution as teaching $(67 \%)$ or non-profit $(60 \%)$ and worked in medical institutions located in an urban setting (73\%). More than half of the respondents (53\%) indicated that they primarily participated in MDT meetings for different types of cancer, with about $47 \%$ reporting typically attending between $80 \%-90 \%$ of the scheduled MDT planning meetings.

\section{Structure of multidisciplinary treatment planning}

Survey responses about the structure of MDTs are reported in Table 2. MDT planning was defined, as "a coordinated approach that brings together multiple cancer specialists such as clinicians as well as other health professionals to plan the appropriate treatment and other integral services for a cancer patient once diagnosis is confirmed." Most of the respondents (73\%) indicated that the survey definition describes some, but not all aspects of the treatment planning approach for cancer patients at their institution, while the remainder of the respondents $(27 \%)$ indicated that the survey definition exactly describes the treatment planning approach at their institution.

More than half of the respondents (53\%) reported that treatment-planning meetings were held on a set schedule, while $27 \%$ reported that these meetings were held as needed, and the remaining $20 \%$ indicated that meetings were held both on a set schedule and as needed. The most common reported frequency of meetings for the treatment planning teams at the participants' institutions was once a week (27\%) and several times a week (27\%). MDT planning meeting mostly occurred in person (53\%) at the participants' institutions, and physicians (80\%) primarily facilitated these meetings. More than half of the respondents $(53 \%)$ reported that patients were immediately made aware of changes to their treatment plans, while $27 \%$ indicated that patients were made aware of these changes within a few days. About $40 \%$ of the participants indicated that the primary method of communication used to update the team members about treatment planning after the meeting was via email.

\section{Patient involvement}

Survey responses about patient involvement in MDT meetings are reported in Table 3. More than half of the respondents $(53 \%)$ indicate that cancer patients, families, and/or caregivers were not invited to participate in MDT planning meetings. In summarizing the respondents' comments regarding why the patients/caregivers were not invited into the meeting, the most common explanation was the fact that 'the discussion may be too overwhelming or confusing for the patient/caregiver'. Regarding the involvement of patients/caregivers attending treatment-planning meetings, the respondents indicated that all asked questions about their care and provided their opinion about treatment options.

\section{Decision support for MDT treatment planning}

Survey responses regarding the decision-making process and communication within the MDT are reported in Tables 4 and 5 respectively. The majority of respondents $(67 \%)$ indicated that positron emission tomography (PET) and computed tomography (CT) were the most common case materials or information available at initial case presentations during MDT meetings, followed by clinician dictations and notes (27\%). Most respondents reported that digital health records (e.g., electronic health records, electronic medical records, patient portals) were instrumental in supporting MDT planning (87\%) and facilitating communication (60\%) with other members of the MDT. Computer programs (e.g., interactive web-based, media) were the type of clinical decision support systems reported to be primarily used during team meetings to make treatment decisions by most of the survey respondents $(60 \%)$, while the remaining $40 \%$ reported the use of no formal decision support system. With regards to how treatment decisions are made after the MDT meeting, most respondents (40\%) indicated that the decision was ultimately made by one person $(40 \%)$ or by vote $(33 \%)$, while the remaining $(27 \%)$ reported that no decisions were made during the meeting.

Most of the respondents (67\%) indicated that the treating physician was the person in charge of delivering an update to patients, families, and/or caregivers after the MDT treatment planning meetings (Table 5). About $60 \%$ of the respondents strongly agree that they felt comfortable about sharing their opinions with others during MDT meetings.

\section{DISCUSSION}

This present study is one of the few evaluating the pharmacists' perspective on the structure, decision-making process, and communication practices of MDTs. Overall, the prevalence of high MDTs attendance ( $\geq 80 \%$ ) was $47 \%$ and MDT meetings were mostly led by physicians. These results are consistent with a study by Horlait et al. (2019) ${ }^{22}$ and other observational studies that found that physicians played a dominant role in MDT meetings. ${ }^{40,41}$ The leadership role of the physicians in MDTs is arguably justified by the fact that they initiate diagnosis and treatment and may play a central role in patient care planning. Furthermore, while the structure of MDTs varies depending upon the characteristics of a particular healthcare institution $^{4}$, organizational factors, ${ }^{22}$ and the population the 
team serves, the prototypical MDT includes a physician, a pharmacist, a nurse, a pathologist, a psychologist, each with a specialized knowledge in oncology.

The analysis of the structure of MDTs revealed an inconsistent definition and a diverging structure of cancer MDTs. With regards to nomenclature, MDT meetings have different names which include, multidisciplinary team meetings, multidisciplinary oncology consultation (MOC), ward meetings, and patient ward rounds. ${ }^{22}$ The frequency of meetings varied between institutions but mostly occurred either once or several times a week. The MDTs meetings mostly occurred in person, were facilitated by physicians, and patients were immediately made aware of the changes in their treatments. One of the main findings from this sample size survey is that while some respondents did not self-identify themselves as oncology pharmacists, they were still involved in the care of cancer patients, and thus were part of a cancer MDT. This finding highlights the expanding roles of clinical pharmacists to land their expertise where cancer treatment decisions are made by the healthcare team. Based on the responses, in most cases, patients were not invited to be part of the treatment planning meetings. Multiple potential barriers have been cited for obstructing patient's participation in MDT in real-life clinical practice. The main barrier is time. ${ }^{42}$ In a previous study members of the MDT felt that any disagreement and difference of opinion in the MDT meeting should be concealed from the patient. ${ }^{43}$ Clinicians face substantial time pressure to efficiently accomplish clinical and patient-related duties, making their time a valuable and scarce resource. These practical challenges may make it difficult to consistently involve patients within the MDT. In other cases, the need to involve the patients in the meetings is not warranted because they often take a passive role in treatment decisions due to several factors including limited health literacy skills, emotional issues, or the inability to perform both basic and instrumental activities. ${ }^{44,45}$ Digital health records appeared to play an important role in supporting the decisions of the MDTs. Digital health records could facilitate verbal communication among members of the MDT. In this context, they can also be used to create, manage and share patient healthcare information efficiently and effectively. ${ }^{38,39}$ Moreover, digital health records may be used to support various forms of electronic communication, such as using remote diagnostics, telemedicine, or video-conferencing. ${ }^{46,47}$

Customarily, the role of oncology pharmacists was limited to safety checks and accurately dispense medication. ${ }^{48}$ However, their role has evolved in recent years, and oncology pharmacists represent a broad range of expertise and levels of practice, skills, and responsibilities within MDTs. ${ }^{48}$ They work with the oncology team to deliver a wide variety of services to patients, including order writing, adverse effect management, education, and supportive care. ${ }^{49,50}$ Oncology pharmacists are regularly utilized for patient education because of their medication expertise. Provision of chemotherapy education programs by oncology pharmacists has been recurrently shown to be associated with improved knowledge of chemotherapy administration and monitoring, and higher rates of patient satisfaction. ${ }^{51-53}$ Aside from their role as patient educators, pharmacists play a central role in medication education for other pharmacists and other healthcare providers. Specifically, they educate other providers to select the most appropriate therapy, accurate medication list, monitor the effects of standard and investigational medications, identify and manage drug interactions, and manage adverse effects. ${ }^{40} \mathrm{~A}$ study conducted by Da Silva (2012) found that the participation of pharmacists in a MDT on an oncological ward was associated with significantly lower rates of drug-related problems. ${ }^{41}$

This study has strengths and some limitations. To our knowledge, this study is the first to evaluate the pharmacists' perspective on MDT structure and decision-making process in Alabama. Thus, it lays a foundation for other studies to be conducted. The study population of pharmacists working in cancer MDTs is very small given that the state of Alabama has relatively fewer number of cancer treatment facilities. ${ }^{42}$ The state has only one National Cancer Institute-designated comprehensive cancer center, ${ }^{43}$ and does not have an Oncology Pharmacists Association; therefore, the ability to identify the pharmacists with expertise in cancer care practicing in the state of Alabama was not readily available. This further entails that the representativeness of responses could not be estimated. A more robust study with a larger sample size is recommended as a next step. Additionally, the role of telemedicine in the participation of various professionals including pharmacists should be examined. Besides, the nature of the study design as a cross-sectional is a limitation because it can introduce response, recall, and selection biases.

\section{CONCLUSIONS}

The management of cancer patients has become more complex given the emergence of new and competing treatments, with various outcomes, side effects, and costs. For instance, in addition to surgery, chemotherapy, targeted pathway inhibition, and radiation therapy, immunotherapy has emerged as a standard pillar of cancer treatment. Furthermore, new agents have been approved based on molecular testing instead of tumor site of origin. MDTs have the potential of improving the quality of life and increasing survival of cancer patients based on the promotion of evidence-based care, and quality assurance of each discipline involved in cancer care. The findings from this study suggests that effective MDTs need pharmacists who understand the multidisciplinary concept. Challenges with the implementation of MDTs persist, and each organization needs to coordinate the implementation and structure of their cancer MDTs based on their sizes, needs, and objectives. However, the implementations and structure of MDTs should consider the adoption of technology, and in particular clinical decision support software to help analyze and classify data and streamline and support workflow as the MDT assembles healthcare information.

The opinions expressed in this paper are those of the author(s).

Funding/Support: None

Conflicts of Interest: None 


\section{REFERENCES}

1. Reeves S, Pelone F, Harrison R, Goldman J, Zwarenstein M. Interprofessional collaboration to improve professional practice and healthcare outcomes. Cochrane Database of Systematic Reviews. 2017(6).

2. Hickman LD, Phillips JL, Newton PJ, Halcomb EJ, Al Abed N, Davidson PM. Multidisciplinary team interventions to optimise health outcomes for older people in acute care settings: a systematic review. Archives of gerontology and geriatrics. 2015;61(3):322-329.

3. Medves J, Godfrey C, Turner C, et al. Systematic review of practice guideline dissemination and implementation strategies for healthcare teams and team-based practice. International Journal of Evidence-Based Healthcare. 2010;8(2):79-89.

4. Lamb BW, Brown KF, Nagpal K, Vincent C, Green JS, Sevdalis $\mathrm{N}$. Quality of care management decisions by multidisciplinary cancer teams: a systematic review. Annals of surgical oncology. 2011;18(8):2116-2125.

5. Sidhom MA, Poulsen MG. Multidisciplinary care in oncology: medicolegal implications of group decisions. The lancet oncology. 2006;7(11):951-954.

6. Du CZ, Li J, Cai Y, Sun YS, Xue WC, Gu J. Effect of multidisciplinary team treatment on outcomes of patients with gastrointestinal malignancy. World journal of gastroenterology: WJG. 2011;17(15):2013-2018.

7. Kim MM, Barnato AE, Angus DC, Fleisher LF, Kahn JM. The effect of multidisciplinary care teams on intensive care unit mortality. Archives of Internal Medicine. 2010;170(4):369376.

8. Balogh EP, Ganz PA, Murphy SB, Nass SJ, Ferrell BR, Stovall E. Patient-centered cancer treatment planning: improving the quality of oncology care. Summary of an Institute of Medicine workshop. The oncologist. 2011;16(12):1800.

9. Dossett LA, Hudson JN, Morris AM, et al. The primary care provider (PCP)-cancer specialist relationship: a systematic review and mixed-methods meta-synthesis. $C A$ : a cancer journal for clinicians. 2017;67(2):156-169.

10. Lim B, Hortobagyi GN. Current challenges of metastatic breast cancer. Cancer and Metastasis Reviews. 2016;35(4):495-514.

11. Sulpher J, Mathur S, Lenihan D, et al. An international survey of healthcare providers involved in the management of cancer patients exposed to cardiotoxic therapy. Journal of oncology. 2015;2015.

12. Scarborough BM, Smith CB. Optimal pain management for patients with cancer in the modern era. CA: a cancer journal for clinicians. 2018;68(3):182-196.

13. Kroschinsky F, Stölzel F, von Bonin S, et al. New drugs, new toxicities: severe side effects of modern targeted and immunotherapy of cancer and their management. Critical Care. 2017;21(1):1-11.

14. Friedland PL, Bozic B, Dewar J, Kuan R, Meyer C, Phillips M. Impact of multidisciplinary team management in head and neck cancer patients. British journal of cancer. 2011;104(8):1246-1248.

15. Ko C, Chaudhry S. The need for a multidisciplinary approach to cancer care. Journal of Surgical Research. 2002;105(1):53-57.
16. Hong NJ, Wright FC, Gagliardi AR, Paszat LF. Examining the potential relationship between multidisciplinary cancer care and patient survival: an international literature review. Journal of surgical oncology. 2010;102(2):125-134.

17. Taylor C, Munro AJ, Glynne-Jones R, et al. Multidisciplinary team working in cancer: what is the evidence? BMJ (Clinical research ed). 2010;340:c951.

18. Hammond D. Multidisciplinary teamwork in the management of childhood cancer. California medicine. 1972;116(3):74.

19. Balch CM. The surgeon's expanded role in cancer care. Cancer. 1990;65(S3 S3):604-609.

20. Rubin P. Comment: The Unidisciplinary vs the Multidisciplinary Approach to Oncology. Jama. 1971;215(3):461-462.

21. Uitdewilligen $\mathrm{S}$, Waller MJ. Information sharing and decision-making in multidisciplinary crisis management teams. Journal of Organizational Behavior. 2018;39(6):731748.

22. Horlait M, Baes S, Dhaene S, Van Belle S, Leys M. How multidisciplinary are multidisciplinary team meetings in cancer care? An observational study in oncology departments in Flanders, Belgium. Journal of multidisciplinary healthcare. 2019;12:159.

23. Klarenbeek SE, Schuurbiers-Siebers OC, van den Heuvel MM, Prokop M, Tummers M. Barriers and facilitators for implementation of a computerized clinical decision support system in lung cancer multidisciplinary team meetings-a qualitative assessment. Biology. 2021;10(1):9.

24. Goud R, de Keizer NF, ter Riet G, et al. Effect of guideline based computerised decision support on decision making of multidisciplinary teams: cluster randomised trial in cardiac rehabilitation. Bmj. 2009;338.

25. Patkar V, Acosta D, Davidson T, Jones A, Fox J, Keshtgar M. Using computerised decision support to improve compliance of cancer multidisciplinary meetings with evidence-based guidance. BMJ open. 2012;2(3):10.1136/bmjopen-2011-000439. Print 002012.

26. Romano MJ, Stafford RS. Electronic health records and clinical decision support systems: impact on national ambulatory care quality. Archives of Internal Medicine. 2011;171(10):897-903.

27. Bates DW, Kuperman GJ, Wang S, et al. Ten commandments for effective clinical decision support: making the practice of evidence-based medicine a reality. Journal of the American Medical Informatics Association. 2003;10(6):523-530.

28. Blumenthal D, Tavenner M. The "meaningful use" regulation for electronic health records. New England Journal of Medicine. 2010;363(6):501-504.

29. Garg AX, Adhikari NKJ, McDonald H, et al. Effects of computerized clinical decision support systems on practitioner performance and patient outcomes: a systematic review. Jama. 2005;293(10):1223-1238.

30. Sittig DF, Wright A, Osheroff JA, et al. Grand challenges in clinical decision support. Journal of Biomedical Informatics. 2008;41(2):387-392.

31. Patkar V, Acosta D, Davidson T, Jones A, Fox J, Keshtgar M. Cancer multidisciplinary team meetings: evidence, challenges, and the role of clinical decision support technology. International journal of breast cancer. 2011;2011. 
32. Elwyn G, Lloyd A, Williams NJ, Beasley A, Tomkinson A. Shared decision-making in a multidisciplinary head and neck cancer team: a case study of developing Option Grids. International Journal of Person Centered Medicine. 2012;2(3):421-426.

33. Doyle J. Barriers and facilitators of multidisciplinary team working: a review. Paediatric Care. 2008;20(2):26-29.

34. Ruhstaller T, Roe H, Thürlimann B, Nicoll JJ. The multidisciplinary meeting: an indispensable aid to communication between different specialities. European journal of cancer. 2006;42(15):2459-2462.

35. Fallowfield $L$, Jenkins $V$. Effective communication skills are the key to good cancer care. European journal of cancer. 1999;35(11):1592-1597.

36. Tyson SF, Burton L, McGovern A. Multi-disciplinary team meetings in stroke rehabilitation: an observation study and conceptual framework. Clinical rehabilitation. 2014;28(12):1237-1247.

37. National Cancer I. Multidisciplinary Treatment Planning Questionnaire. In:2012.

38. Reeves S, Pelone F, Harrison R, Goldman J, Zwarenstein M. Interprofessional collaboration to improve professional practice and healthcare outcomes. Cochrane Database of Systematic Reviews. 2017(6).

39. Hickman LD, Phillips JL, Newton PJ, Halcomb EJ, Al Abed N, Davidson PM. Multidisciplinary team interventions to optimise health outcomes for older people in acute care settings: a systematic review. Archives of gerontology and geriatrics. 2015;61(3):322-329.

40. Medves J, Godfrey C, Turner C, et al. Systematic review of practice guideline dissemination and implementation strategies for healthcare teams and team-based practice. International Journal of Evidence-Based Healthcare. 2010;8(2):79-89.

41. Lamb BW, Brown KF, Nagpal K, Vincent C, Green JS, Sevdalis N. Quality of care management decisions by multidisciplinary cancer teams: a systematic review. Annals of surgical oncology. 2011;18(8):2116-2125.

42. Sidhom MA, Poulsen MG. Multidisciplinary care in oncology: medicolegal implications of group decisions. The lancet oncology. 2006;7(11):951-954.

43. Du CZ, Li J, Cai Y, Sun YS, Xue WC, Gu J. Effect of multidisciplinary team treatment on outcomes of patients with gastrointestinal malignancy. World journal of gastroenterology : WJG. 2011;17(15):2013-2018.

44. Kim MM, Barnato AE, Angus DC, Fleisher LF, Kahn JM. The effect of multidisciplinary care teams on intensive care unit mortality. Archives of Internal Medicine. 2010;170(4):369376.

45. Balogh EP, Ganz PA, Murphy SB, Nass SJ, Ferrell BR, Stovall E. Patient-centered cancer treatment planning: improving the quality of oncology care. Summary of an Institute of Medicine workshop. The oncologist. 2011;16(12):1800.

46. Dossett LA, Hudson JN, Morris AM, et al. The primary care provider (PCP)-cancer specialist relationship: a systematic review and mixed-methods meta-synthesis. CA: a cancer journal for clinicians. 2017;67(2):156-169.

47. Lim B, Hortobagyi GN. Current challenges of metastatic breast cancer. Cancer and Metastasis Reviews. 2016;35(4):495-514.
48. Sulpher J, Mathur S, Lenihan D, et al. An international survey of healthcare providers involved in the management of cancer patients exposed to cardiotoxic therapy. Journal of oncology. 2015;2015.

49. Scarborough BM, Smith CB. Optimal pain management for patients with cancer in the modern era. $C A$ : a cancer journal for clinicians. 2018;68(3):182-196.

50. Kroschinsky F, Stölzel F, von Bonin S, et al. New drugs, new toxicities: severe side effects of modern targeted and immunotherapy of cancer and their management. Critical Care. 2017;21(1):1-11.

51. Friedland PL, Bozic B, Dewar J, Kuan R, Meyer C, Phillips M. Impact of multidisciplinary team management in head and neck cancer patients. British journal of cancer. 2011;104(8):1246-1248.

52. Ko C, Chaudhry S. The need for a multidisciplinary approach to cancer care. Journal of Surgical Research. 2002;105(1):53-57.

53. Hong NJ, Wright FC, Gagliardi AR, Paszat LF. Examining the potential relationship between multidisciplinary cancer care and patient survival: an international literature review. Journal of surgical oncology. 2010;102(2):125-134.

54. Taylor C, Munro AJ, Glynne-Jones R, et al. Multidisciplinary team working in cancer: what is the evidence? BMJ (Clinical research ed). 2010;340:c951.

55. Hammond D. Multidisciplinary teamwork in the management of childhood cancer. California medicine. 1972;116(3):74.

56. Balch CM. The surgeon's expanded role in cancer care. Cancer. 1990;65(S3 S3):604-609.

57. Rubin P. Comment: The Unidisciplinary vs the Multidisciplinary Approach to Oncology. Jama. 1971;215(3):461-462.

58. Uitdewilligen S, Waller MJ. Information sharing and decision-making in multidisciplinary crisis management teams. Journal of Organizational Behavior. 2018;39(6):731748.

59. Horlait M, Baes S, Dhaene S, Van Belle S, Leys M. How multidisciplinary are multidisciplinary team meetings in cancer care? An observational study in oncology departments in Flanders, Belgium. Journal of multidisciplinary healthcare. 2019;12:159.

60. Klarenbeek SE, Schuurbiers-Siebers OC, van den Heuvel MM, Prokop M, Tummers M. Barriers and facilitators for implementation of a computerized clinical decision support system in lung cancer multidisciplinary team meetings-a qualitative assessment. Biology. 2021;10(1):9.

61. Goud R, de Keizer NF, ter Riet G, et al. Effect of guideline based computerised decision support on decision making of multidisciplinary teams: cluster randomised trial in cardiac rehabilitation. Bmj. 2009;338.

62. Patkar V, Acosta D, Davidson T, Jones A, Fox J, Keshtgar M. Using computerised decision support to improve compliance of cancer multidisciplinary meetings with evidence-based guidance. BMJ open. 2012;2(3):10.1136/bmjopen-2011-000439. Print 002012.

63. Romano MJ, Stafford RS. Electronic health records and clinical decision support systems: impact on national ambulatory care quality. Archives of Internal Medicine. 2011;171(10):897-903. 
64. 2Bates DW, Kuperman GJ, Wang S, et al. Ten commandments for effective clinical decision support: making the practice of evidence-based medicine a reality. Journal of the American Medical Informatics Association. 2003;10(6):523-530.

65. Blumenthal D, Tavenner M. The "meaningful use" regulation for electronic health records. New England Journal of Medicine. 2010;363(6):501-504.

66. Garg AX, Adhikari NKJ, McDonald H, et al. Effects of computerized clinical decision support systems on practitioner performance and patient outcomes: a systematic review. Jama. 2005;293(10):1223-1238.

67. Sittig DF, Wright A, Osheroff JA, et al. Grand challenges in clinical decision support. Journal of Biomedical Informatics. 2008;41(2):387-392.

68. Patkar V, Acosta D, Davidson T, Jones A, Fox J, Keshtgar M. Cancer multidisciplinary team meetings: evidence, challenges, and the role of clinical decision support technology. International journal of breast cancer. 2011;2011.

69. Elwyn G, Lloyd A, Williams NJ, Beasley A, Tomkinson A. Shared decision-making in a multidisciplinary head and neck cancer team: a case study of developing Option Grids. International Journal of Person Centered Medicine. 2012;2(3):421-426.

70. Doyle J. Barriers and facilitators of multidisciplinary team working: a review. Paediatric Care. 2008;20(2):26-29.

71. Ruhstaller $T$, Roe $H$, Thürlimann B, Nicoll JJ. The multidisciplinary meeting: an indispensable aid to communication between different specialities. European journal of cancer. 2006;42(15):2459-2462.

72. Fallowfield L, Jenkins V. Effective communication skills are the key to good cancer care. European journal of cancer. 1999;35(11):1592-1597.

73. Tyson SF, Burton L, McGovern A. Multi-disciplinary team meetings in stroke rehabilitation: an observation study and conceptual framework. Clinical rehabilitation. 2014;28(12):1237-1247.

74. National Cancer I. Multidisciplinary Treatment Planning Questionnaire. In:2012.

75. Janssen A, Robinson T, Brunner M, Harnett $P$, Museth KE, Shaw T. Multidisciplinary teams and ICT: a qualitative study exploring the use of technology and its impact on multidisciplinary team meetings. BMC health services research. 2018;18(1):1-10.

76. Aghdam MRF, Vodovnik A, Hameed RA. Role of telemedicine in multidisciplinary team meetings. Journal of pathology informatics. 2019;10.

77. Holle LM, Boehnke Michaud L. Oncology pharmacists in healthcare delivery: vital members of the cancer care team. Journal of oncology practice. 2014;10(3):e142-e145.

78. da Silva NM. The impact of pharmacist participation in a multidisciplinary team on an oncology ward compared with a ward clinical pharmacy service. Eur J Hosp Pharm Sci Pract. 2012;19(2):259-260.

79. Patient Resources LLC. Alabama Cancer Treatment Facilities. Patient Resource LLC. https://www.patientresource.com/Facilities by State.aspx. Published 2020. Accessed October 10, 2020, 2020.
80. National Cancer Institute. National Cancer Institute Designated Cancer Centers.

https://www.cancer.gov/research/infrastructure/cancercenters/find/uabccc. Published 2020. Updated March 2, 2020. Accessed October 10, 2020.

81. Kidger J, Murdoch J, Donovan J, Blazeby J. Clinical decisionmaking in a multidisciplinary gynaecological cancer team: a qualitative study. BJOG: An International Journal of Obstetrics \& Gynaecology. 2009;116(4):511-517.

82. Dew K, Stubbe M, Signal L, et al. Cancer care decision making in multidisciplinary meetings. Qualitative health research. 2015;25(3):397-407.

83. Pieterse AH, Stiggelbout AM, Montori VM. Shared decision making and the importance of time. Jama. 2019;322(1):2526.

84. Hamilton DW, Heaven B, Thomson RG, Wilson JA, Exley C. Multidisciplinary team decision-making in cancer and the absent patient: a qualitative study. BMJ open. 2016;6(7):e012559.

85. de Angst IB, Kil PJ, Bangma CH, Takkenberg JJ. Should we involve patients more actively? Perspectives of the multidisciplinary team on shared decision-making for older patients with metastatic castration-resistant prostate cancer. Journal of geriatric oncology. 2019;10(4):653-658.

86. Brabers AE, Rademakers JJ, Groenewegen PP, Van Dijk L, De Jong JD. What role does health literacy play in patients' involvement in medical decision-making? PloS one. 2017;12(3):e0173316.

87. Janssen A, Robinson T, Brunner M, Harnett P, Museth KE, Shaw T. Multidisciplinary teams and ICT: a qualitative study exploring the use of technology and its impact on multidisciplinary team meetings. $B M C$ health services research. 2018;18(1):1-10.

88. Aghdam MRF, Vodovnik A, Hameed RA. Role of telemedicine in multidisciplinary team meetings. Journal of pathology informatics. 2019;10.

89. Vulaj V, Hough S, Bedard L, Farris K, Mackler E. Oncology pharmacist opportunities: closing the gap in quality care. Journal of oncology practice. 2018;14(6):e403-e411.

90. La CH, Franco M, Grewal G, McLeod V, Segelov E. An expanded role oncology pharmacist adds value to symptom and urgent review clinics. Asia-Pacific Journal of Clinical Oncology. 2018.

91. M Segal E, Bates J, Fleszar SL, et al. Demonstrating the value of the oncology pharmacist within the healthcare team. Journal of Oncology Pharmacy Practice. 2019;25(8):19451967.

92. Muluneh B, Schneider M, Faso A, et al. Improved adherence rates and clinical outcomes of an integrated, closed-loop, pharmacist-led oral chemotherapy management program. Journal of oncology practice. 2018;14(6):e324-e334.

93. McKee M, Frei BL, Garcia A, Fike D, Soefje SA. Impact of clinical pharmacy services on patients in an outpatient chemotherapy academic clinic. Journal of Oncology Pharmacy Practice. 2011;17(4):387-394.

94. Crespo A, Tyszka M. Evaluating the patient-perceived impact of clinical pharmacy services and proactive followup care in an ambulatory chemotherapy unit. Journal of Oncology Pharmacy Practice. 2017;23(4):243-248. 
95. Fisher CM, Kim AJ, Elder JJ. Impact of a pharmacist-led chemotherapy education program on the knowledge of pediatric hematology/oncology nurses. The Journal of Pediatric Pharmacology and Therapeutics. 2017;22(5):332337.

96. Holle LM, Boehnke Michaud L. Oncology pharmacists in healthcare delivery: vital members of the cancer care team. Journal of oncology practice. 2014;10(3):e142-e145.

97. da Silva NM. The impact of pharmacist participation in a multidisciplinary team on an oncology ward compared with a ward clinical pharmacy service. Eur J Hosp Pharm Sci Pract. 2012;19(2):259-260.

98. Patient Resources LLC. Alabama Cancer Treatment Facilities. Patient Resource LLC.

https://www.patientresource.com/Facilities by State.aspx. Published 2020. Accessed October 10, 2020, 2020.

99. National Cancer Institute. National Cancer Institute Designated Cancer Centers.

https://www.cancer.gov/research/infrastructure/cancercenters/find/uabccc. Published 2020. Updated March 2, 2020. Accessed October 10, 2020. 
Table 1. Demographic characteristics of respondents $(\mathrm{N}=15)$

\begin{tabular}{|c|c|}
\hline Demographic Characteristics & Response distribution, $\mathrm{n}(\%)$ \\
\hline \multicolumn{2}{|l|}{ Gender } \\
\hline Female & $8(53)$ \\
\hline Male & $7(47)$ \\
\hline \multicolumn{2}{|l|}{ Age group (years) } \\
\hline 35- 44 & $12(80)$ \\
\hline $55-64$ & $3(13)$ \\
\hline 65 and older & $1(7)$ \\
\hline \multicolumn{2}{|c|}{ Geographic location of the practice } \\
\hline Urban & $11(73)$ \\
\hline Suburban & $4(27)$ \\
\hline \multicolumn{2}{|l|}{ Hospital ownership } \\
\hline Non-Profit & $9(60)$ \\
\hline For-Profit & $6(40)$ \\
\hline \multicolumn{2}{|l|}{ Healthcare delivery setting } \\
\hline Teaching & $10(67)$ \\
\hline Non-teaching & $5(33)$ \\
\hline \multicolumn{2}{|l|}{ Number of beds } \\
\hline$>500$ & $1(7)$ \\
\hline $400-499$ & $1(7)$ \\
\hline $300-399$ & $4(27)$ \\
\hline $200-299$ & $5(33)$ \\
\hline $100-199$ & $2(13)$ \\
\hline$<99$ & $2(13)$ \\
\hline \multicolumn{2}{|l|}{ Professional practice group } \\
\hline Oncology pharmacy & $5(33)$ \\
\hline Ambulatory care pharmacy & $3(20)$ \\
\hline Clinical Pharmacy & $3(20)$ \\
\hline Consulting Pharmacy & $1(7)$ \\
\hline Hospital Pharmacy & $3(20)$ \\
\hline \multicolumn{2}{|l|}{ Number of years in practice } \\
\hline $6-10$ years & $7(47)$ \\
\hline $11-15$ years & $5(33)$ \\
\hline $16-20$ years & $2(13)$ \\
\hline Over 20 years & $1(7)$ \\
\hline \multicolumn{2}{|c|}{ Type of cancer primarily attending MDT for } \\
\hline Carcinoma & $3(20)$ \\
\hline Lymphoma & $1(7)$ \\
\hline Sarcoma & $1(7)$ \\
\hline Mixed types & $8(53)$ \\
\hline General & $2(15)$ \\
\hline \multicolumn{2}{|c|}{ Percentage MDT meetings attending } \\
\hline $80 \%-100 \%$ & $7(47)$ \\
\hline $50 \%-79 \%$ & $3(20)$ \\
\hline $20 \%-49 \%$ & $1(7)$ \\
\hline Less than $20 \%$ & $4(27)$ \\
\hline
\end{tabular}


Table 2. Structure of multidisciplinary treatment planning

\begin{tabular}{|l|l|}
\hline The occurrence of MDT meetings & Response distribution, $\mathbf{n}$ (\%) \\
\hline Set schedule & $8(53)$ \\
\hline As needed & $4(27)$ \\
\hline Both (As needed or on a set schedule) & $3(20)$ \\
\hline Frequency of MDT meetings & \\
\hline Once a day & $2(13)$ \\
\hline Several times a day & $1(7)$ \\
\hline Once a week & $4(27)$ \\
\hline Several times a week & $4(27)$ \\
\hline Once a month & $1(7)$ \\
\hline Once every few months & $1(7)$ \\
\hline Varies & $2(13)$ \\
\hline Setting of MDT meeting & \\
\hline In-person & $8(53)$ \\
\hline Virtually & $4(27)$ \\
\hline Both (In-person and virtually) & $3(20)$ \\
\hline Meeting facilitator & \\
\hline Physician & $12(80)$ \\
\hline Pharmacist & $2(13)$ \\
\hline Clerical staff & $1(7)$ \\
\hline Frequency of team updates & \\
\hline Immediately & $8(53)$ \\
\hline Within a few days & $4(27)$ \\
\hline Within a week or two & $1(7)$ \\
\hline Not until the next team meeting & $2(13)$ \\
\hline The primary method of communication for team & \\
\hline updates & $6(40)$ \\
\hline Email & $3(20)$ \\
\hline In-person discussion at the next team meeting & $5(33)$ \\
\hline Updates to the patient's electronic medical record & $1(7)$ \\
\hline Text messages & \\
\hline
\end{tabular}

Table 3. Patients and caregivers participation to MDT meetings

\begin{tabular}{|c|l|}
\hline Patients' invitation to MDT meetings & Response distribution, $\mathbf{n}(\%)$ \\
\hline Yes & $7(47)$ \\
\hline No & $8(53)$ \\
\hline $\begin{array}{l}\text { Type of Patient involvement } \\
\text { Osked questions about their care, }\end{array}$ & \\
\hline Others & $7(47)$ \\
\hline
\end{tabular}


Table 4. Decision Support for MDT

\begin{tabular}{|l|l|}
\hline Materials or information available at initial case presentations & Response distribution, $\mathbf{n}$ (\%) \\
\hline $\begin{array}{l}\text { Positron emission tomography (PET) computed tomography (CT) and other radiology } \\
\text { films and reports }\end{array}$ & $10(67)$ \\
\hline Clinician dictations or notes & $4(27)$ \\
\hline Diagnostic test results & $1(7)$ \\
\hline How useful are digital health records to support MDT treatment planning? & \\
\hline Very useful & $13(87)$ \\
\hline Somewhat useful & $2(13)$ \\
\hline As a means of communication, digital health records are mostly useful for? & \\
\hline $\begin{array}{l}\text { Facilitating communication with other providers that are part of the multidisciplinary } \\
\text { team }\end{array}$ & $9(60)$ \\
\hline $\begin{array}{l}\text { Facilitating communication with other providers that are not part of the } \\
\text { multidisciplinary team and may work in outside institutions }\end{array}$ & $6(40)$ \\
\hline Types of clinical decision support systems used during team & \\
\hline Computer program (e.g., interactive web-based, media) & $9(60)$ \\
\hline No formal decision support system is used & $6(40)$ \\
\hline How are treatment decisions ultimately made? & \\
\hline Decisions are made by one person & $6(40)$ \\
\hline Decisions are made by a vote & $5(33)$ \\
\hline No decisions are made during the meeting & $4(27)$ \\
\hline
\end{tabular}

Table 5. MDT Communication

\begin{tabular}{|l|l|}
\hline Who primarily delivers updates to patients, families, and/or caregivers, if necessary & Response distribution, $\mathbf{n}(\%)$ \\
\hline Physician & $10(67)$ \\
\hline Pharmacist & $2(13)$ \\
\hline Allied health professional & $1(7)$ \\
\hline Nurse & $1(7)$ \\
\hline Someone else & $1(7)$ \\
\hline I feel comfortable sharing my opinion with team members. & \\
\hline Strongly agree & $9(60)$ \\
\hline Agree & $3(20)$ \\
\hline Neither agree nor disagree & $3(20)$ \\
\hline
\end{tabular}

